\title{
Real-Time New Product Development in Financial Services: Some Managerial Implications
}

\author{
Pete Naudé \\ Manchester Business School \\ Manchester, United Kingdom \\ p.naude@fs2.mbs.ac.uk
}

Steve Dengler
Xenon Laboratories
Toronto, Canada
sdengler@xe.com

\author{
Ian Blackman \\ Manchester Business School \\ Manchester, United Kingdom \\ 100776.2760@compuserve.com
}

\begin{abstract}
A review of the various models of New Product Development (NPD) process shows that although different approaches have been proposed, they are in fact all variants on a linear theme: some may include feedback loops, but they all essentially advocate that certain steps precede, or are preceded by, others. An inevitable consequence on the Internet/World Wide Web $(W W W$ or Web) is that such models are no longer applicable. Based on the lessons learned from the development of a new financial service offered via the Internet, we show how such assumptions of linearity need no longer be a constraint. In addition, innovativeness is not related to firm size. But the fact that the Web allows for the real-time development of new financial services based on on-going feedback from potential and current customers raises a new set of managerial issue that have to be tackled. The objective of this paper is to use the context of the recent launch of an innovative financial services product via the Web to explore the managerial changes that are starting to affect the banking industry.
\end{abstract}

\section{Introduction}

The need to develop new products in the short term in order to ensure longer term survival is a fact of life. Companies are facing pressure from both demand-pull and technology-push. On the one hand, increasingly sophisticated customers are demanding ever more (usually technology-based) value for their money; while we also find rival companies taking advantage of barriers to entry that are often declining due to the application of new technologies from other industries.

Obviously, those companies that can introduce products that succeed in the market place stand to gain at the expense of those who systematically introduce products that fail. Unfortunately, just what constitutes a success or a failure of a product or service remains a problem bedevilled by definitions of 'newness' and measurement of 'success' (Baker, 1991; Crawford, 1987). However, in spite of these difficulties, research does suggest that management is improving its performance: the success rate has climbed from about $1 \%$ or $2 \%$ in the 1960 s to a more respectable $10-15 \%$ in the 1980s (Booz-Allen \& Hamilton, 1982; Kotler and Armstrong, 1987). It is likely that a major reason for this increase in the success rate is the fact that past research has allowed managers to understand the process better, and hence allowed them the benefit of planning their NPD process based more on a knowledge of the underlying model and process than on luck.

A variety of these models exist (e.g. Booz-Allen and Hamilton, 1982; Kotler, 1983; Donnelly et al., 1985; Johnson et al., 1986; Bowers, 1986; Cooper, 1988). However, there are two common aspects that characterise all of these approaches: they are all linear models, and are based on the development of products rather than of services. In terms of linearity, the modellers have tended to see the NPD process as consisting of a number of steps that are both sequential and distinct. Only Cowell (1988) 
raises the issue of parallel processing, but his model is still predicated upon the belief that some aspects of the process have to precede others (projects may need to be "put on hold" while other elements of the process are concluded).

The extent to which services marketing does or does not constitute a separate area of marketing is largely an academic question. However, it does seem judicious to accept that those working in the area of NPD within the services industry need not totally re-invent the NPD process, and that they can "benefit considerably from existing knowledge of the new product development and launch process derived from studies of consumer products and new industrial products" (Cowell, 1988:311). Earlier research has found that service based companies did indeed approach their NPD process in a different way to product oriented companies (Easingwood, 1986). First, the underlying simultaneity of production and consumption implies that operational staff have to deliver the new services that the marketing department may introduce, and may thereby affect both delivery of the service and the generation of new ideas. Secondly an implication of the intangibility of service is that it is relatively easy to introduce new product variants, to the potential confusion of both staff and customers.

But what about the financial services sector in particular? Although there are characteristics of the industry that lead to the advantage that the introduction of new products that subsequently fail is not as financially detrimental as it is in other industries (Davison et al., 1989) there are still the problems of lost time and managerial effort. Where the success or failure of new products has been tested (see, for example, Easingwood and Storey, 1991), the results have been geared towards what we would see as the more traditional end of the banking industry: of delivering new products through traditional channels of distribution, using the traditional methods of reaching the customer in order to assess the extent to which a service fulfils a need, and then using the traditional marketing channels to sell that service and to hopefully set up a longer term relationship with that customer.

\section{The context of this paper}

In this paper our objective is to extend the debate to a more novel issue: to move beyond just what the implications of the Web are, and to examine the (not always welcome) managerial/organisational implications of this new channel of communication. This is based on the experiences of the authors gained via the recent introduction of a new financial service product offered on the Web.

The Banking industry world-wide is having to face up to significant structural changes in its environment such as deregulation, globalisation, disintermediation, as well as the implications of rapid advances in what can be achieved with IT systems. All these point to long term decline in profitability within the banking industry (Holland et al., 1996; 1997), which makes the introduction of new products as a source of future earnings even more important. Most banks, however, still focus on increasing income from their existing broad base of customers, and reducing their own costs rather than growing market share across a global market segment. There has been considerable discussion on the potential of the Internet as a potential solution to this problem (Foremski, 1996). Indeed, the cost of accessing customers in the international market place have plunged, and it is now as easy for a customer in Singapore to access a service in New York as it is for a local customer. This use of the Web represents a significant advantage over the earlier excitement of simply using database marketing as a competitive tool (e.g. Blattberg and Deighton, 1991).

Banks and other financial institutions have been developing electronic means of delivering products since the mid 1970's. There were a number of reasons behind this change in approach. These included the desire to:

* reduce processing costs by eliminating manual processing by the service provider

* remove capacity restraints

* improve the timeliness of the response to customers

* reduce the occurrence of errors by minimising the rekeying of information

* reduce head-count

From the bankers' perspective, the electronic services were developed as alternatives to the existing manual processes that were well understood by both provider and customer. Previous research has shown that two important issues arise when financial services are offered via the Web. These are that there is still considerable risk attached to using this channel (from both provider and buyer perspectives) and that it is often the smaller providers that are the more innovative (Yan et al., 1997). However, the rise of the Web technology has meant that a whole new range of products can be offered, products that are not attempting to provide the old products better, but products that are totally new. But this move has brought about a new range of problems: while financial institutions have successfully delivered electronic systems that mimic existing processes, they have faced considerable difficulty in testing concepts that utilise the benefits of an electronic system to change the existing working process. This is shown in Figure 1, where the $\mathrm{x}$ axis shows the sale of financial services linked to either 
single/simple products (current account, repayment mortgage) or else complex packaged financial solutions using a combination of financial processes (derivatives, combining funding and management of financial risk of an export), and the $y$-axis representing the mode of delivery.

It is our contention that banks that are unable to offer automated processes to meet the needs of their customer base will have difficulty in producing services to meet the specific needs of individual segments. Increasingly, they will find that the products they can provide are only economic for large value transactions. For example a large number of banks are able to structure complex financial structures to cover specific financial risks identified by the customer. To make the transaction economic for both the customer and the bank the margin charged by the bank needs to be below the perceived economic benefit of covering the risk in the first place. This can and is achieved when corporations hedge their overall foreign exchange exposure with individual transactions valued in millions of dollars. It is doubtful that a corporation would be willing to pay the bank's

charges for manually producing a contract to cover the foreign exchange risk on a contract worth less that $\$ 20,000$. There are also capacity limitations where a bank's dealer would be sensitive to the fact that the time spent on a small value deal could be spent with another customer with a large transaction. It is increasingly clear that the unit cost of meeting customers' requirements can be greatly reduced, and at the same time the capacity restraints of the existing manual process removed, by providing an automated service that is accessible to the customer.

In terms of Figure 1, we would argue that Block 1 does

\section{PRODUCT}

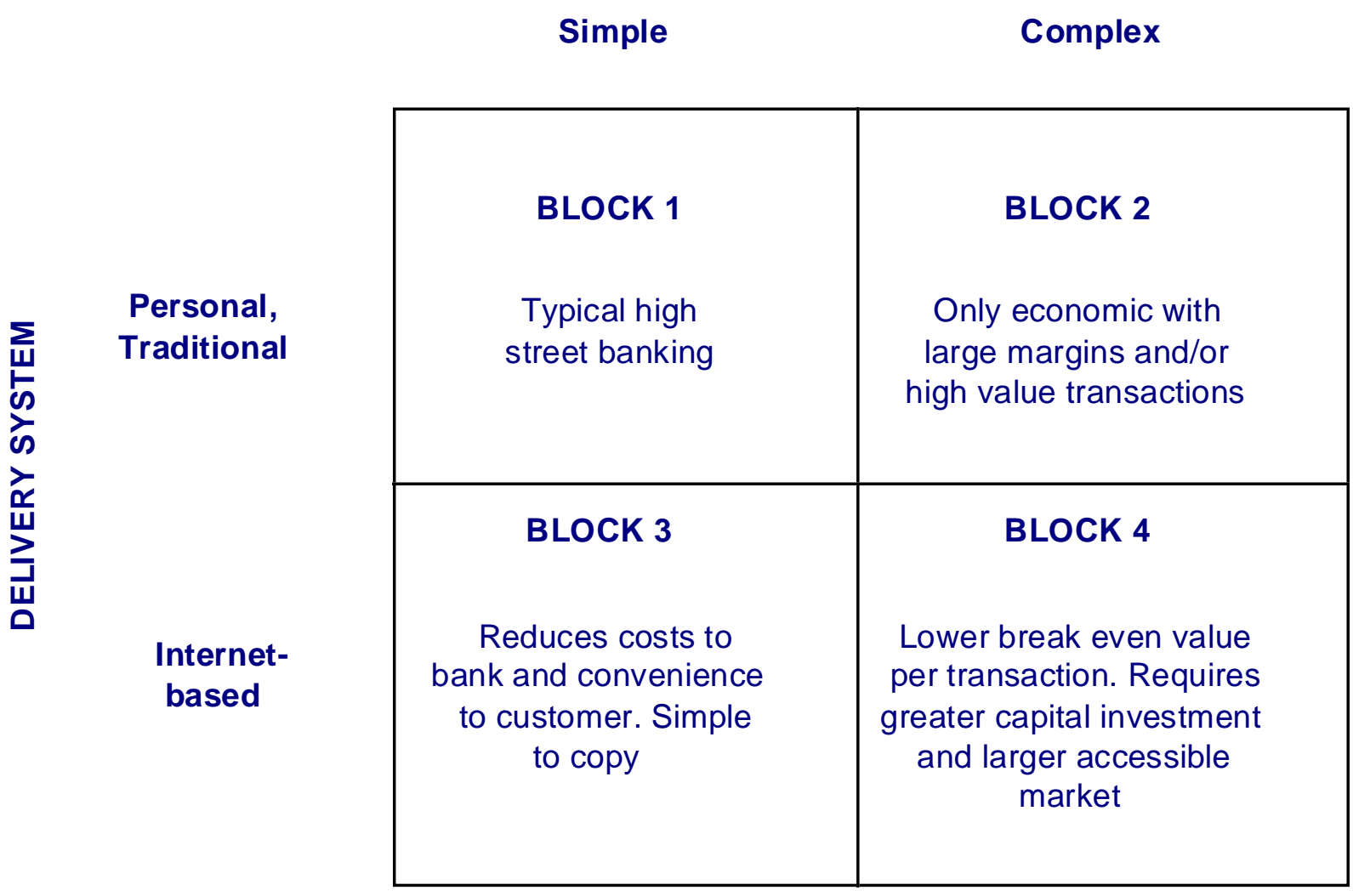

Figure 1. Areas of new product development in the banking industry 
not represent a secure future for any modern bank offering existing products via the traditional personal channels of distribution. In this category we would include 'new' technologies such a ATMs and telephone banking. Block 3 presents an obvious solution: offering products with which both bank and customers are familiar, but utilising the Internet as a new, cheaper, and faster channel of delivery. This is typical of what is happening with electronic banking systems such as PCbased banking - it is only the delivery system that is new (i.e. it is the technology providers who are being innovative, not the banks), and the route is open to all players in the field. Block 2, complex products that are delivered using traditional means require a high transaction value and margin to provide an adequate return to the bank, thus limiting their application. We would argue, therefore, that the true innovations for the banking industry must come from the electronic banking that lies in Block 4, where new products are designed to be delivered in new ways. Naturally, this route is usually perceived as the most risky, given the typically high development costs involved, as well as the market share required to make acceptable returns, both of which make it difficult to test market proto-types. But is this traditional view of the risks associated with diversification still true? We would hope that the accompanying case study shows that it is not.

\section{Developing product concepts in the banking industry: current problems and inadequacies}

The last few years have seen a huge increase in the number of products/services available in the financial services industry. From a bank's perspective, it is relatively simple to develop an initial concept and to define the expected benefits to the customers based on the features required. However, difficulties have always arisen in testing the validity of IT-based products aimed at the financial institution marketplace. A number of practical issues have to be resolved:

\section{3:1 Identifying Potential Customers}

Based on a formal or informal idea generation stage, it is relatively easy for those familiar with a bank's product range to develop products which they believe have unique and advantageous features. The problem arises in identifying the size and nature of the target market likely to benefit from the innovation. Unless factors are already used to identify customers in a central database (annual turnover, asset base, etc.) there is considerable difficulty in determining which of the existing customers are most suited to the new service. Alternatively there are large numbers of staff in financial institutions that work with the customers on a regular basis that can be used to identify potential customers. However, this is a valid approach only when dealing with a narrow target market (i.e. multinational corporations). The logistical effort required to ensure that the staff dealing with a broader market (small to medium sized corporations or retail customers) understand the concept and can identify their own clients that would be suitable to test the product, makes the approach at best expensive and time consuming and at worst impractical. While in practice market research companies can be used to identify a suitable base of existing and potential customers, this approach is only really effective for the few large full-service banks that have the advantage of a significant share of the customer base (say 15-30\%).

\section{3:2 Concept Feedback from Potential Customers}

Once a sample of customers have been personally identified, it is a relatively simple if onerous task to interview them in order to solicit feedback on the benefits of the proposed product so as to calculate their perception of the value of those benefits. Assuming that the response from the customer base is sufficiently positive, a demonstration prototype can be developed and tested with groups of customers either individually or more commonly in user groups. The process is time consuming for the customers whichever route is taken.

From the customer feedback a beta system can be developed, which then has to be integrated into the institutions' internal processing systems which in turn serves as the basis for feedback regarding the ease of use and durability of the system. As appealing as this process sounds, reality dictates that it takes in the region of eighteen months (with an aggressively managed program) to complete this process. Pressure on decreasing the time to market means that there tends to be considerable pressure to launch the service without major changes required by specific market segments, since once the service is shown to operate adequately it can be marketed to a broad customer base.

\subsection{Accessing a Broad Enough Customer Base}

Full service banks tend to operate predominantly in single national or regional markets where they have a significant market share (one of the few exceptions is Citibank that provides retail financial services in a large number of countries). As banks tend to serve the needs of a broad range of customer segments in relatively small markets, the number of customers in a specific customer segment is correspondingly small. There is a tendency to broaden the features of the product to satisfy the basic requirements of a number of segments to ensure a large enough group of customers can be accessed to warrant the investment. The danger is that the focus of the 
service is lost and few of the customers are completely satisfied.

\subsection{Obtaining Feedback from Customers}

Once the service is live, customer feedback can be gathered with user forums to determine the priority for the upgrades required to improve the system. Increasingly, email functionality is used by a number of financial institutions to enable customers to provide feed back on the electronic service used and to contact customer service staff.

\subsection{Identifying Suitable Customers}

The initial problem of identifying customers that would benefit from the new service remains when attempting to sell the service to existing and new customers. It is easier to attract the attention of the staff that are dealing with the customers on a day to day basis once a product is available. The level of understanding of a particular market segment's requirements and the benefits and features of the service delivered to meet those requirements will be at best be limited. A large portion of the work of branch based staff is involved in reacting to requests from customers (processing payments and loans). A separate set of competencies is required by the staff to act in a proactive manner to identify the needs of specific customers and match the products available within the bank.

\section{6 Responding to Customer Requests in a Timely Fashion}

Finally, a large portion of existing electronic banking solutions require the customer to install a piece of software specific to the bank. Upgrading the service requires the reinstallation of a new release of the software to enable the customer to access the benefits of the new service. This creates a number of problems, such as the reluctance to roll out an improved version of the software until an acceptable base of customers is using the initial service; the number of modifications required to be made to justify second roll out; and difficulty in prioritising requests from customers covering a number of segments. It is not possible to evolve a service by making small changes to the service in timely fashion to respond to customer requests. As each version of the service involves significant changes, the customer base often needs to be resold the service and trained to use the upgrade.

\section{Lessons from a Case Study: Building and Exploiting a Customer Base on the Internet}

We have outlined above some of the issues that are of concern to the banking industry when using Web technology. With this context in mind, the authors worked with a Canadian Internet service company (Xenon Laboratories) in order both to explore how the Web technology can be used to dramatically lower the barriers mentioned above, and also to identify the managerial implications of using the technology.

In August 1995 Xenon launched a simple calculator service that enabled users of their Web page to input a value, state its currency and request a calculation of the equivalent value in a second currency. The initial intention of the company was to generate an income from the service by charging for advertising targeted at companies and people interested in foreign exchange. While the number of times the calculator was used on a daily basis grew steadily over the first year, the numbers were insufficient to interest potential users of the advertising space. However, the free currency service remained successful in attracting a large and growing group of customers interested in information on foreign exchange. The usage of the calculator was exceeding 200000 hits per week (September 1997), amounting to a compound growth of $0.6 \%$ per day.

Xenon's statistics indicated that a significant number of customers were using their calculator on a daily basis. However, as the customers were accessing a public page there was no way of identifying the individual users and initially it was not known why the customers were using the service. A second service was launched in March 1996 where customers were e-mailed daily foreign exchange (FX) rate sheets expressed against the customers' choice of currency. The service proved to be popular with the additional benefit that the customers were required to fill in a simple registration form

including their e-mail address to use the service. The information from the registration forms gave the first indication of the geographic distribution of the customer base and the functional roles of the users. The database identified a broad geographic spread of customers (over 50 countries) with a high proportion of key decision 


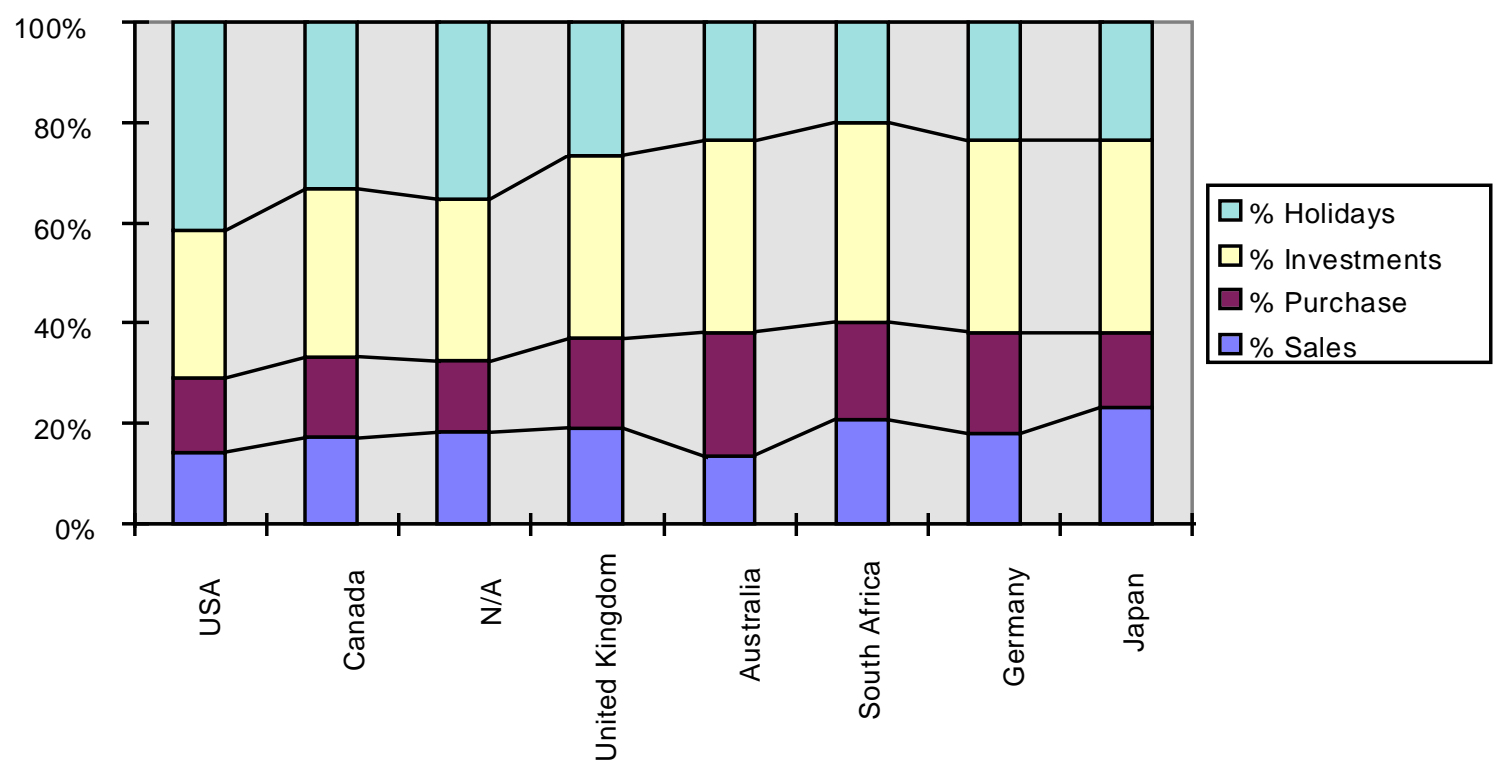

Figure 2. Key usage of service by country

makers (over 20\% described themselves as company CEOs or owners). By September 199723000 emails were being sent out per day (the net growth exceeding $0.4 \%$ per day). The broad appeal of the service is indicated by Figure 2, showing both the key usage of the service and the origin of the user (based on a sample of 8000 users in June 1997). Figure 3 indicates how the number of users increased over time.

Given the broad customer base, it was decided to exploit this advantage and use the address list to test a concept for a new financial service. The service was aimed at exporters world wide, the objective being to offer a service that :

* simply processed the price in the customer's currency

* confirmed the value of funds to be received in the exporter's local currency at the time the sale was agreed

* reduced delays and costs in receiving funds by includ-

ing detailed payment routing advice with the invoice

* could be accessed through their existing bank relationship.

In order to test the concept, a simple questionnaire was developed and placed on the Web page. An initial sample of approximately 380 customers using the e-mail service were sent a note requesting their input and given the Web address of the questionnaire. Within three days 61 replies (16\%) had been received directly into a central database. The quick response demonstrated the technology's aid in administering questionnaires over a wide geographic area, greatly reducing the cost and lead time in collecting responses, and removing the need to rekey the responses into a database. A further benefit for the people involved in the development of the service was to be able to quickly and directly respond to customer questions sent as separate e-mails, rather than having to rely on a market research group to relay issues in a final report.

While the initial responses indicated that the service would be attractive to a significant portion of the customer base, a number of questions remained to be answered. However, as only a small (easily identifiable) portion of the total customer base had been contacted in the initial test, a series of additional tests could be performed without asking individual customers to respond more than once. The key product issue to be resolved was the determination of the level of functionality required to satisfy the largest proportion of customers. A working demonstration of the proposed system was developed and put onto the main web page with access controlled by a password. A second group of customers were then emailed with a short description of the service, given the location and password to access the service and asked for their feedback. Input from each of the tests enabled the 
service to be refined to the point where there was sufficient confidence in the understanding of the customers' requirements to develop a working system.

This process indicated that a cycle of developing a design hypothesis and questionnaire/ demonstration, issuing the e-mails with the address of the demonstration, collecting and analysing the customer responses, using the feedback to modifying the demonstration and questionnaire to test outstanding issues, and finally reissuing the e-mails to separate customer group could be repeated with a cycle time of less than four weeks with the largest portion of the time taken in analysing and discussing the output from the surveys. In addition, the large size and geographic spread of the customer base used to test the service provided additional benefits in terms of being able to determine the national/regional markets that offered the greatest potential for the service, to build a database of customers expressing an interest in the service, and to actively involve interested customers in the development of the service.

\section{The Managerial Implications of the New}

\section{Technology}

From observing what has happened within Xenon as a result of the launch of the new service, it became clear that the managerial implications of using the new Webbased technology will affect organisations in a number of

ways, some of which are technology oriented and obvious, the others more subtle and unexpected.

At the obvious end of the spectrum, it is clear that the process of using customer feedback to improve service has been enhanced. The iterative approach to testing prototypes over the Web will become standard practice. In addition, a benefit offered by browser platforms used to access the Internet is that the customer does need to load software specific to the service. The software operating the financial service used by the customers is held centrally on the servers of the company offering the service. As there is not a need to reissue and install software updates to the customer, suggestions from customers can be implemented on the service without impacting the customer base. This enables the service to

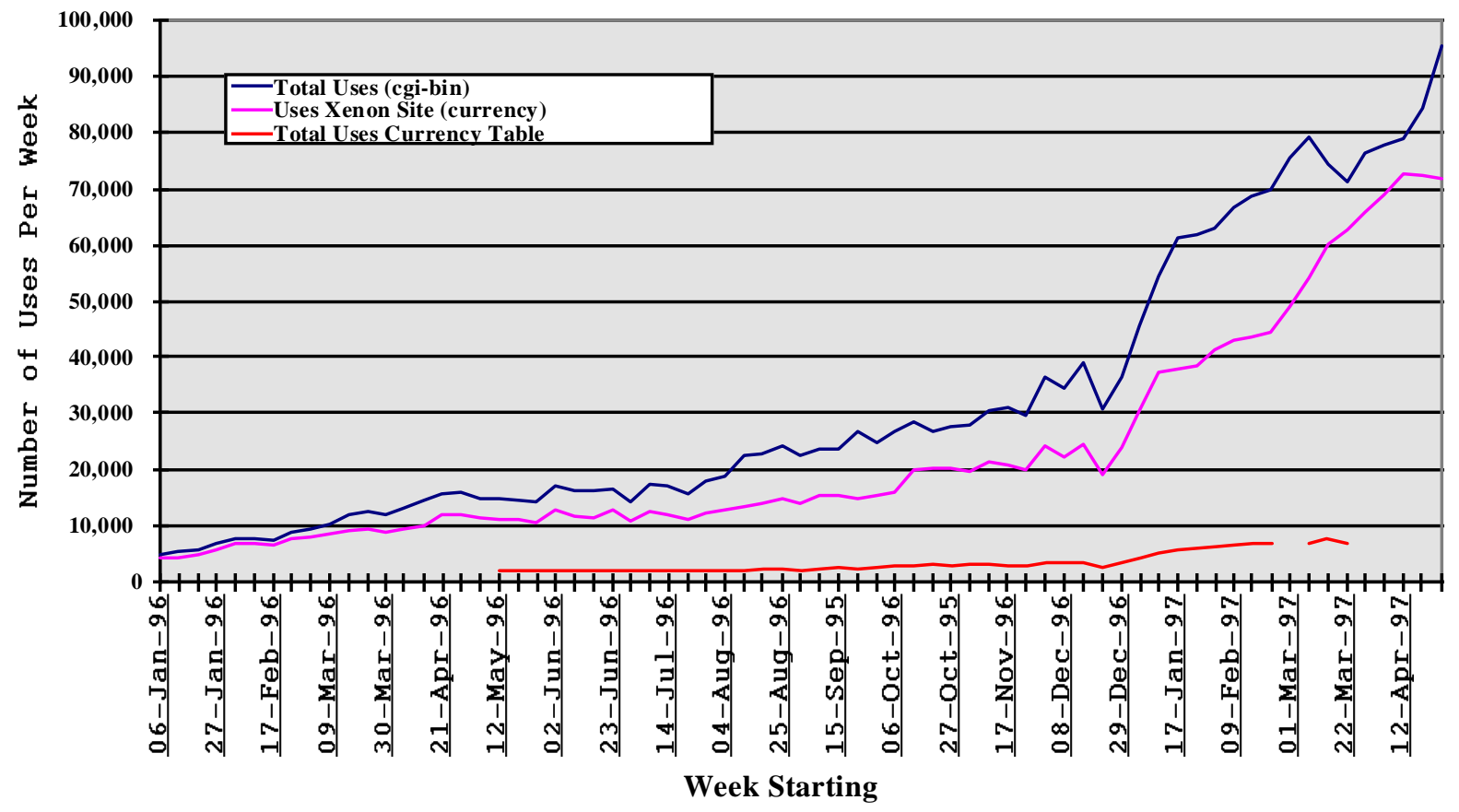

Figure 3. Actual uses of Currency Converter 
be developed with a series of simple iterations, allowing the service to be enhanced without the need to retrain the customers in the new functionality. In addition, major developments and future releases of the service can be made accessible to existing customers through a demonstration Web pages, allowing feedback to be provided before major changes or enhancements are made. The key benefit is to enable the service provider both to prompt and to react to developments in the market with very short lead times.

It is clear that the internet/WWW will increasingly be used as an avenue for market research (Comley, 1996; Quelch and Klein, 1996; Yan et al., 1997). However, as this case indicated, the possibility now exists to use the technology to build more of relationship between buyer and supplier, to the extent where the interaction adds more value than traditional market research (see also Quinn et al., 1996; Johne \& Pavlidis, 1996). Potential advantages lie in the fact that a new channel of communication exists for relationship building between customer and supplier, whereby customers are not exposed to yet more market research, but rather become an integral part of the NPD process itself. While this blurring of the lines between market research and NPD is something that we see as exciting and inevitable, it does also imply that customer's expectation levels will be raised, which puts additional innovative pressure on the supplier.

As far as suppliers are concerned, however, a number of benefits of using this new channel of communication accrue, all of which combine to both lower the cost of market research and yet to increase its usefulness. Once a customer database has been built up, the major benefit is that new service concepts can be developed to meet the perceived needs of the customer group which can then be tested within very short lead times. Not only are response rates likely to be relatively high because of the novelty of the approach, but the quality of feedback is enhanced given that the research is undertaken in context. Customers can 'see' the actual service being researched. In addition, the costs are low. The first mover who builds a global customer base benefits from the fact that costs of doing research are relatively independent of size, and barriers to entry are low. Finally, there are benefits to the quality of the research in that feedback is fast, allowing incremental changes to be made to the service which can immediately be assessed, thereby lowering the probability of introducing a service that will not be accepted by the market.

While these advantages occur at an operational level, there are potential benefits too in terms of longer term competitive advantage. Traditional providers of financial services who do not adopt this approach will have difficulty in responding to competitors targeting the needs of global market segments. However, this raises a number of issues surrounding the management process itself. For example, there is the potential for existing providers of financial services to build global brands serving specific market segments, either by extending their own customer base or by providing branded services to other financial service companies to sell to their own customers. Within a relatively short period, a significant gap could open up between the perceived value of new or established entrants using the Internet to access and deliver financial services compared with financial service providers using traditional means of delivery (branch networks). This will put pressure on the traditional service providers. To retain the value of their existing brands in their own national market, service providers will need to offer a range of services that are recognised as meeting the needs of each of the market segments. We believe that increasingly they will not be able to do this, given the low entry costs associated with internet-based, niche-oriented, global operators. New entrants that have developed databases of international customers interested in a specific market problem, with contact maintained via the Internet, have an advantage in testing concepts compared to traditional financial institutions that have large but unfocused national customer data bases and who maintain their contact through traditional distribution channels.

Second, we believe that the decision making process underpinning the NPD process will need to change from the currently centralised process to one that enables the investment decisions to be made by the managers involved in the actual customer communication. Rather than sanctioning large scale investments with long lead times, banks will need to organise their business units to mirror customer segments, with the ability to make incremental investments in improving customer services. The total profitability of specific segments will need to be measured over a period of time to determine the success of projects. To remain competitive, each bank will need to determine which market segments it is able to focus on to develop its own solutions. Rather than accepting the loss of customers in the market segments where the bank does not have a distinct advantage, they will need to actively pursue an initiative to either buy-in services or partner other institutions to provide a service that is capable of keeping up with market developments.

By moving the process for decision making within the organisation, there are implications for the banks' own ability to manage the overall investment budget. There is a danger that by making a series of small incremental investments following the developments of any market leader, relatively large investments will be made over a short period time without obtaining a recognisable advantage. While the investment may enable the following bank to retain a portion of its own customer 
base and related revenue, the bank would not benefit from a significant increase in customer numbers and would suffer from a higher fixed support cost for the resulting developments to the enhanced service capability. Alternatively, the individual managers may not be able to invest enough to keep up with the market leaders in the segment resulting in a steady reduction in market share, combined with an overall increase in the bank's fixed cost base.

Senior managers in the universal banks typically have a background in risk management (i.e. lending) and have developed their management skills in vertically integrated business groups where they have control of the largest part of the components that make up the service delivered to the customer. It is our belief that expertise in bank marketing skills have not mirrored the rapid development in financial services offerings that have come about as a result of developments in information technology. To keep up with the developments in the market, banks' senior management need to develop new skills to handle the increase in autonomy required to proactively seek out customer requirements and where necessary agree formal business arrangements with external suppliers.

Finally, it has traditionally been true that a large portion of the status and reward for senior managers within universal banks has been directly related to the size of the organisation that they control. It is our belief that partnering with outside organisations will increase as a way of offering new technology-based products to increasingly segmented groups of customers. Only in this way can links with customers be maintained and medium to long term income streams be stabilised. However, the immediate result is to reduce the direct control of the senior management and reduce the size of the organisation that they manage. There must therefore be a significant change in the reward system within banks to recognise and encourage the actions of management in reducing the fixed cost base of the bank and enhancing the quality of the service offered to the existing customer base.

\section{6: Conclusion}

The traditional rules relating to market research and NPD are being rewritten. The use of real-time processes means that financial institutions have to recognise that the traditional distinction between market research and NPD is blurring, resulting in decreased time to market coupled, paradoxically, with the ability to do research incrementally and yet to build closer relationships with customers at the same time. However, there are implications relating not just to the research process, but also to more strategic issues. We posit that the low costs involved in offering Web-based financial services will see the growth of global, niche-oriented players, to the detriment of the traditional full-service provider. If this view is correct, there follow important implications about the way in which staff in the more traditional financial services sectors are managed and rewarded.

\section{References}

Baker, M., Marketing: An Introductory Text, London: Macmillan, 1991

Blattberg, R.C. and Deighton, J., Interactive Marketing: Exploiting the age of Adressability, Sloan Management Review, 33:1, pp. 5-14, 1991

Booz-Allen and Hamilton, Management of New Products, New York: Booz-Allen and Hamilton, 1968

Booz-Allen \& Hamilton, New Product Management for the 1980s, New York: Booz, Allen and Hamilton, 1982

Bowers, M. R., The New Product Development Process: A Suggested Model for Banks, Journal of Retail Banking, (8), pp. 19-24, 1986

Comley, P., Internet Surveys: The Use of the Internet as a Data Collection Method, Proceedings of the ESOMAR/EMAC Symposium on Research Methodologies for the New Marketing, ESOMAR Publication Series Vol 204, pp. 335-346, 1996

Cooper, R. G., The New Product Development Process: A Decision Guide for Management, Journal of Marketing Management, (3:3), pp. 238-255, 1988

Cowell, D. W., New Service Development, Journal of Marketing Management, (3:3), pp. 296-312, 1988

Crawford, C. M., New Product Failure Rates, A Reprise, Research Management, (XXX:4), pp. 20-24, 1987

Davison, H., Watkins, T., and Wright, M., Developing New Personal Financial Products - Some Evidence on the Role of Market Research, International Journal of Bank Marketing, (7:1), pp. 8-15, 1989

Donnelly, J. H., Berry, L.L., and Thompson, T. W., Marketing Financial Services, Homewood, Illinois: Dow Jones-Irwin, 1985

Easingwood, C. J., New Product Development for Service Companies, Journal of Product Innovation Management, (3:4), pp. 264-275, 1986 
Easingwood, C.J. and Storey, C., Success factors for New Consumer Financial Services, International Journal of Bank Marketing, (9:1), pp. 3-10, 1991

Foremski, T., Web Browsers Beat Bricks and Mortar, Financial Times IT Supplement, Sept 4th, pp. IV, 1996

Holland, C.P., Lockett, A. G., and Blackman, I. D., The Impact of Globalisation and Information Technology on the Strategy and Profitability of the Banking Industry, in Sprague R.H. and J. F. Nunamaker (Eds.), Proceedings of the 30th Hawaii International Conference on System Sciences (1996)

Holland, C.P., Lockett, A. G., and Blackman, I. D., The Business Impact of Information Technology on the Banking Industry, Paper presented at AIS Academy of Information Systems, Phoenix, Arizona, August 16-18, 1996

Johne, F. A. and Pavlidis, M. P., How Banks Apply Marketing Expertise to Develop New Derivatives, Journal of Product Innovation Management, 13:5, pp. 440-452, 1996
Johnson, E. M., Scheuing, E. E., and Gaida, K. A., Profitable Service Marketing, Homewood, Illinois: Dow Jones-Irwin, 1986

Kotler, P., Principles of Marketing, London: PrenticeHall, 1983

Kotler, P. and Armstrong, G., Principles of Marketing, London: Prentice-Hall, 1980

Quelch, J.A. and Klein, L.R., The Internet and International Marketing, Sloan Management Review, $37: 3$, pp. 60-75, 1996

Quinn, J. B., Baruch, J. J., and Zien, K. A., SoftwareBased Innovation, Sloan Management Review, Summer, pp. 11-24, 1996

Yan, G., Paradi, J.C., and Bhargava, S., Banking on the Internet and its Applications, in Sprague R.H. and J. F. Nunamaker (Eds.), Proceedings of the 30th Hawaii International Conference on System Sciences (1996) 